\title{
Response
}

\section{Hypoglycemia and Dementia Risk in Older Patients with Type 2 Diabetes Mellitus: A Propensity-Score Matched Analysis of a Population-Based Cohort Study (Diabetes Metab J 2020;44:125-33)}

\author{
Seung Jin Han
}

Department of Endocrinology and Metabolism, Ajou University School of Medicine, Suwon, Korea

We thank Dr. Kim for expressing interest and giving comments on our article entitled "Hypoglycemia and dementia risk in older patients with type 2 diabetes mellitus: a propensity-score matched analysis of a population-based cohort study" which was published in Diabetes \& Metabolism Journal [1].

We agree with Dr. Kim's suggestion of the potential impact of diabetes duration on the dementia risk. However, the Korean Health Insurance Review and Assessment Service database does not contain information on the duration of diabetes. Microvascular and macrovascular complications of diabetes were matched as factors for the severity of diabetes instead of the duration of diabetes. Concomitant diabetic complications are the final indicator of the severity of diabetes. In the subgroup analysis, hypoglycemia was associated with an increased risk of dementia in with or without type 2 diabetes mellitus microvascular or macrovascular complications.

Research into the link between glucose fluctuation and dementia risk has already investigated. Li et al. [2] showed that glycemic variability, determined by coefficient of variation of fasting plasma glucose and glycated hemoglobin was associated with Alzheimer disease independent of traditional risk factors in Taiwanese with type 2 diabetes mellitus. Rawlings et al. [3] demonstrated that serum 1,5-anhydroglucitol levels, indicative of glycemic peaks are a risk factors of cognitive decline and dementia over 20 years in subjects with diabetes.

Based on your comments of the severity of hypoglycemia, we suspect that hypoglycemia coded in this study may indicate relatively severe hypoglycemia not mild. As we have already discussed this as a limitation, clinicians tend not to record hypoglycemia in practice, especially in mild case, when entering diagnostic codes. Smoking is well-known, modifiable risk factor for cognitive decline and dementia. Unfortunately, these data were not available for this study [4].

We also agree further prospective studies with long term follow periods are needed to confirm our findings in other populations. Thank you again for your interest in our research and your thoughtful comments.

\section{CONFLICTS OF INTEREST}

No potential conflict of interest relevant to this article was reported.

\section{REFERENCES}

1. Kim YG, Park DG, Moon SY, Jeon JY, Kim HJ, Kim DJ, Lee KW, Han SJ. Hypoglycemia and dementia risk in older patients with type 2 diabetes mellitus: a propensity-score matched anal-
Corresponding author: Seung Jin Han (iD https://orcid.org/0000-0003-4783-6799 Department of Endocrinology and Metabolism, Ajou University School of Medicine, 164 World cup-ro, Yeongtong-gu, Suwon 16499, Korea

E-mail: hsj@ajou.ac.kr
This is an Open Access article distributed under the terms of the Creative Commons Attribution Non-Commercial License (https://creativecommons.org/licenses/by-nc/4.0/) which permits unrestricted non-commercial use, distribution, and reproduction in any medium, provided the original work is properly cited. 
ysis of a population-based cohort study. Diabetes Metab J 2020; 44:125-33.

2. Li TC, Yang CP, Tseng ST, Li CI, Liu CS, Lin WY, Hwang KL, Yang SY, Chiang JH, Lin CC. Visit-to-visit variations in fasting plasma glucose and $\mathrm{HbAlc}$ associated with an increased risk of Alzheimer disease: Taiwan diabetes study. Diabetes Care 2017; 40:1210-7.
3. Rawlings AM, Sharrett AR, Mosley TH, Ballew SH, Deal JA, Selvin E. Glucose peaks and the risk of dementia and 20-year cognitive decline. Diabetes Care 2017;40:879-86.

4. Anstey KJ, von Sanden C, Salim A, O’Kearney R. Smoking as a risk factor for dementia and cognitive decline: a meta-analysis of prospective studies. Am J Epidemiol 2007;166:367-78. 